\section{Commentary: You want to do WHAT with my patient?!?}

Danisa K. Daubenspeck, DO, ${ }^{a}$

Husam H. Balkhy, MD, ${ }^{b}$ Valluvan Jeevanandam, MD, ${ }^{c}$ and Mark A. Chaney, $\mathrm{MD}^{\mathrm{d}}$

The decision to take a patient to the catheterization lab or back to the operating room (OR) for suspected myocardial ischemia (MI) immediately after surgery is not a small one. Nicolas and colleagues ${ }^{1}$ present an adequate overview of the advantages and disadvantages of the various modalities that clinicians use while pondering this issue and even include an algorithm. However, we believe important clinical factors/options were not appropriately addressed and suggest that there should be a modification of the algorithm described for this rare dilemma.

Assessment and diagnosis of MI after surgery should begin in the OR. Several tools are available to measure flow or patency. Intraoperative angiography is the gold standard and can be performed in the OR after closure, which may help diagnose issues such as graft distortion, although equipment availability, and cost limit its use. ${ }^{2,3}$ Transit time flow measurement uses ultrasonography to measure flow (mean graft flow, pulsatility index, and diastolic filling percentage) and is used primarily in off-pump coronary artery bypass grafting. ${ }^{2,45}$ Transesophageal echocardiography can detect regional wall motion abnormalities decreases in biventricular function, and has been used to assess graft flow., ${ }^{2,6}$

The authors describe the use of electrocardiography, biomarkers, and hemodynamics as the primary means of assessing for MI and using echocardiography if those variables are inconclusive. Biomarkers are not as useful after cardiac

From the ${ }^{\mathrm{a} D e p a r t m e n t ~ o f ~ A n e s t h e s i a ~ a n d ~ C r i t i c a l ~ C a r e, ~}{ }^{\mathrm{b}}$ Robotic and Minimally Invasive Cardiac Surgery, Section of Cardiac Surgery, Department of Surgery, ${ }^{\mathrm{c} C a r d i a c}$ Surgery, Section of Cardiac Surgery, Department of Surgery, Heart and Vascular Center, and ${ }^{\mathrm{d}}$ Cardiac Anesthesia, Department of Anesthesia and Critical Care, University of Chicago Medical Center, Chicago, Ill.

Disclosures: The authors reported no conflicts of interest.

The Journal policy requires editors and reviewers to disclose conflicts of interest and to decline handling or reviewing manuscripts for which they may have a conflict of interest. The editors and reviewers of this article have no conflicts of interest.

Received for publication Aug 16, 2021; revisions received Aug 16, 2021; accepted for publication Aug 17, 2021; available ahead of print Aug 21, 2021.

Address for reprints: Mark A. Chaney, MD, Department of Anesthesia and Critical Care, University of Chicago Medical Center, 5841 South Maryland Ave, MC 4028, Chicago, IL 60637 (E-mail: MChaney@dacc.uchicago.edu).

J Thorac Cardiovasc Surg 2023;165:1202-3

$0022-5223 / \$ 36.00$

Copyright $₫ 2021$ Published by Elsevier Inc. on behalf of The American Association for Thoracic Surgery

https://doi.org/10.1016/j.jtcvs.2021.08.045

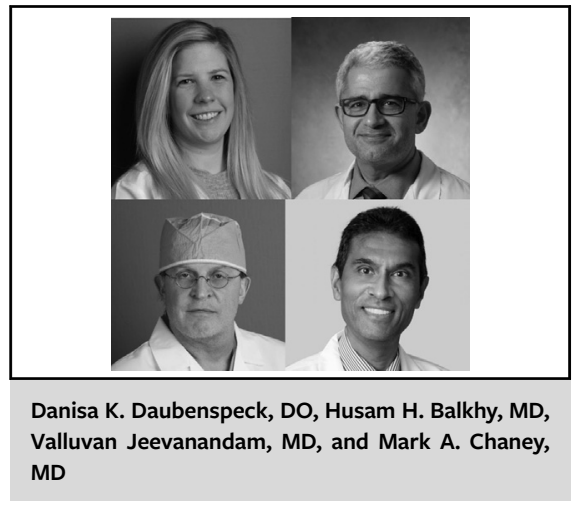

CENTRAL MESSAGE

With suspected myocardial

ischemia after cardiac surgery, diagnosis in the catheterization lab should be the first step, with severe hemodynamic instability prompting early use of mechanical support.

surgery where most patients will have elevated levels and time for results can delay diagnosis. ${ }^{7}$ In the hemodynamically unstable patient, echocardiography provides a quick assessment of function, detection of regional wall motion abnormalities, and can distinguish other causes of hemodynamic instability. Transthoracic echocardiography may be more readily available and is less invasive; however, since most patients post-cardiac surgery are intubated, transesophageal echocardiography can be used and may be able to provide more detailed information.

Important considerations when determining next steps include patient characteristics and the surgery performed. Patients who are post-coronary artery bypass grafting are often more tolerant of coronary ischemia due to preexisting disease and collateral circulation. Repeat surgery is high risk, and long-term outcomes must be considered. Hemodynamic instability should not be a limiting factor to the patient going to the catheterization lab. Calcium channel blockers can be used with suspected vasospasm (which can occur in both radial and mammary grafts), and using mechanical assistance (intra-aortic balloon pump or extracorporeal membrane oxygenation) can provide support as a bridge to intervention. The first step should be to go to the catheterization lab for diagnosis. In the case of catastrophic ischemia, mechanical support should be used. 
Once a diagnosis is confirmed, intervention can occur in the catheterization lab or, after discussion with the surgeon, the patient can return to the OR.

In the end, the decision to intervene is typically made by the cardiac surgeon after accounting for preoperative, intraoperative, and postoperative factors and close consultation with intensivists and cardiologists. Such a rare (our institution reports an incidence of $<1 \%$ ) complex clinical scenario requires contemplation of numerous factors before choosing the optimal clinical path for a specific patient.

\section{References}

1. Nicolas J, Soriano K, Salter B, Gross CR, Oloomi M, Dangas G. Myocardial infarction after cardiac surgery: when to intervene? J Thorac Cardiovasc Surg. 2023; 165:1195-201.
2. Fukui T. Intraoperative graft assessment during coronary artery bypass surgery Gen Thorac Cardiovasc Surg. 2015;63:123-30.

3. Hol PK, Lingaas PS, Lundblad R, Rein KA, Vatne K, Smith HJ, et al. Intraoperative angiography leads to graft revision in coronary artery bypass surgery. Ann Thorac Surg. 2004;78:502-5; discussion 505.

4. Di Giammarco G, Marinelli D, Foschi M, Di Mauro M. Intraoperative graft verification in coronary surgery. J Cardiovasc Med (Hagerstown). 2017;18: 295-304.

5. D'Ancona G, Karamanoukian HL, Ricci M, Bergsland J, Salerno TA. Graft patency verification in coronary artery bypass grafting: principles and clinical applications of transit time flow measurement. Angiology. 2000;51: 725-31.

6. Akiyama K, Arisawa S, Ide M, Iwaya M, Naito Y. Intraoperative cardiac assessment with transesophageal echocardiography for decision-making in cardiac anesthesia. Gen Thorac Cardiovasc Surg. 2013;61:320-9.

7. Thielmann M, Sharma V, Al-Attar N, Bulluck H, Bisleri G, Bunge JJH, et al ESC Joint Working Groups on cardiovascular surgery and the cellular biology of the heart position paper: perioperative myocardial injury and infarction in patients undergoing coronary artery bypass graft surgery. Eur Heart J. 2017; 38:2392-407.
See Article page 1195 .

\section{Commentary: Myocardial infarction after cardiac surgery: Putting it all together}

\author{
Christopher Wilcox, DO, ${ }^{\mathrm{a}}$ Nikolhaus Smith, MD, ${ }^{\mathrm{b}}$ and \\ Glenn J. R. Whitman, MD
}

In their expert opinion, Nicolas and colleagues ${ }^{1}$ discuss the difficult clinical scenario of postcardiac surgery (PCS) myocardial infarction (MI). Diagnosing active ischemia early is critical to mitigating the negative sequelae of PCSMIs, ${ }^{1}$ namely reducing infarct size to preserve ventricular function. In acknowledging the dilemma we all face, the authors summarize the limitations in the data available to us in the immediate postoperative phase of care, eg, patients who are intubated or sedated and unable to give a clinical history, poststernotomy chest pain as a common postoperative

\footnotetext{
From the ${ }^{\mathrm{a}}$ Division of Cardiac Surgery, Department of Surgery, and ${ }^{\mathrm{b}}$ Division of Cardiology, Department of Medicine, Johns Hopkins University School of Medicine, Baltimore, Md.

Disclosures: The authors reported no conflicts of interest.

The Journal policy requires editors and reviewers to disclose conflicts of interest and to decline handling or reviewing manuscripts for which they may have a conflict of interest. The editors and reviewers of this article have no conflicts of interest.

Received for publication Aug 24, 2021; revisions received Aug 24, 2021; accepted for publication Aug 24, 2021; available ahead of print Aug 27, 2021.

Address for reprints: Glenn J. R. Whitman, MD, Division of Cardiac Surgery, Department of Surgery, Johns Hopkins University School of Medicine, Baltimore, MD

21287 (E-mail: gwhitman@jhmi.edu).

J Thorac Cardiovasc Surg 2023;165:1203-4

$0022-5223 / \$ 36.00$

Copyright (c) 2021 by The American Association for Thoracic Surgery

https://doi.org/10.1016/j.jtcvs.2021.08.055
}

Check for updates

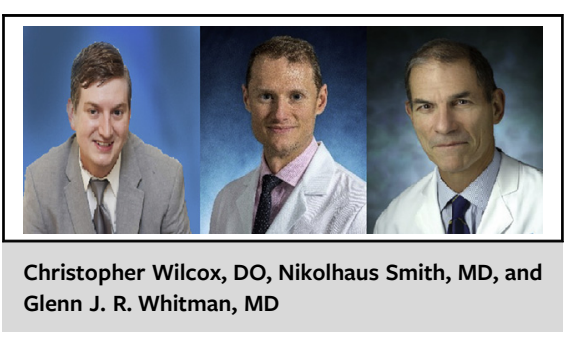

CENTRAL MESSAGE

Early identification of patients

with $\mathrm{Ml}$ after cardiac surgery is

difficult, but this well-presented

algorithm can make the choice

of watchful waiting or immedi-

ate action an easier one to

make.

complaint, worrisome ST-segment changes, which can be normal findings after cardiac surgery, troponin elevations, which are nonspecific and seen in more than $90 \%$ of PCS to some degree, ${ }^{2}$ and suboptimal echocardiogram windows for the evaluation of wall motion abnormalities. Aiming to overcome these difficulties, the authors propose an algorithm to simplify the diagnostic approach to PCS-MI. 